\title{
Satellite- versus temperature-derived green wave indices for predicting the timing of spring migration of avian herbivores
}

\author{
Mitra Shariati Najafabadi ${ }^{\mathrm{a}, *}$, Roshanak Darvishzadeh ${ }^{\mathrm{a}}$, Andrew K. Skidmore ${ }^{\mathrm{a}}$, \\ Andrea Kölzsch ${ }^{\mathrm{b}, \mathrm{c}}$, Anton Vrieling ${ }^{\mathrm{a}}$, Bart A. Nolet ${ }^{\mathrm{c}}$, Klaus-Michael Exo ${ }^{\mathrm{d}}$, \\ Nirvana Meratnia ${ }^{\mathrm{e}}$, Paul J.M. Havinga ${ }^{\mathrm{e}}$, Julia Stahl ${ }^{\mathrm{f}}$, Albertus G. Toxopeus ${ }^{\mathrm{a}}$ \\ a Faculty of Geo-Information Science and Earth Observation (ITC). University of Twente, PO Box 217, 7500 AE Enschede, The Netherlands \\ ${ }^{\mathrm{b}}$ Max Plank Institute for Ornithology, Department of Migration and Immuno-Ecology, 78315 Radolfzell, Germany \\ ' Department of Animal Ecology and Project Group Movement Ecology, Netherlands Institute of Ecology (NIOO-KNAW), 6708 PB Wageningen, The \\ Netherlands \\ d Institute of Avian Research, An der Vogelwarte 21, 26386 Wilhelmshaven, Germany \\ e Faculty of Electrical Engineering, Mathematics and Computer Science (EEMCS), University of Twente, PO Box 217, 7500 AE Enschede, The Netherlands \\ ${ }^{f}$ Sovon Dutch Centre for Field Ornithology, PO Box 6521, 6503 GA Nijmegen, The Netherlands
}

Keywords:

GWI index

GDD jerk index

Barnacle geese

Stopover site

Breeding site

Mixed effect linear regression

\begin{abstract}
A B S T R A C T
According to the green wave hypothesis, herbivores follow the flush of spring growth of forage plants during their spring migration to northern breeding grounds. In this study we compared two green wave indices for predicting the timing of the spring migration of avian herbivores: the satellite-derived green wave index (GWI), and an index of the rate of acceleration in temperature (GDDjerk). The GWI was calculated from MODIS normalized difference vegetation index (NDVI) satellite imagery and GDDjerk from gridded temperature data using products from the global land data assimilation system (GLDAS). To predict the timing of arrival at stopover and breeding sites, we used four years (2008-2011) of tracking data from 12 GPS-tagged barnacle geese, a long-distance herbivorous migrant, wintering in the Netherlands, breeding in the Russian Arctic. The stopover and breeding sites for these birds were identified and the relations between date of arrival with the date of $50 \% \mathrm{GWI}$ and date of peak GDDjerk at each site were analyzed using mixed effect linear regression. A cross-validation method was used to compare the predictive accuracy of the GWI and GDDjerk indices. Significant relationships were found between the arrival dates at the stopover and breeding sites for the dates of $50 \% \mathrm{GWI}$ as well as the peak GDDjerk $(p<0.01)$. The goose arrival dates at both stopover and breeding sites were predicted more accurately using GWI $\left(R_{c v}^{2}=0.68\right.$, $\operatorname{RMSD}_{c v}=5.9$ and $R_{c v}^{2}=0.71, \operatorname{RMSD}_{c v}=3.9$ for stopover and breeding sites, respectively) than GDDjerk. The GDDjerk returned a lower accuracy for prediction of goose arrival dates at stopover $\left(R_{c v}^{2}=0.45\right.$, $\left.\operatorname{RMSD}_{c v}=7.79\right)$ and breeding sites $\left(R_{c v}^{2}=0.55, \operatorname{RMSD}_{c v}=4.93\right)$. The positive correlation between the absolute residual values of the GDDjerk model and distance to the breeding sites showed that this index is highly sensitive to latitude. This study demonstrates that the satellite-derived green wave index (GWI) can accurately predict the timing of goose migration, irrespective of latitude and therefore is suggested as a reliable green wave index for predicting the timing of avian herbivores spring migration.
\end{abstract}

\section{Introduction}

The green wave hypothesis predicts that herbivores time their spring migration to take advantage of the flush of nutrient-rich plants at each stopover site toward their breeding grounds (Owen, 1980). In support of the green wave hypothesis, it was observed that the timing of the annual northern migration of geese coincided with plant phenology (Van der Graaf et al., 2006). Arrival to the breeding site usually happens prior the peak of nutrient biomass, since it provides a better chance to profit from high food 
quality for hatched goslings and molting adults (Prop and de Vries, 1993; Sedinger and Flint, 1991; Van der Graaf et al., 2006). The phenological patterns of migratory animals (including birds) such as migration timing are responsive to climate change (Root et al., 2003). However, it still remains unclear whether timing of avian herbivores migration coincides with the phenology of food source, i.e. the date of first spring flush of plants, which in turn determines food availability for migratory birds (Visser and Both, 2005). Spring advancement, which results from climate change, is more rapid in high-latitude Arctic regions than further south. This may advance food availability more at higher latitude compared to lower latitude, where spring migration begins (IPCC, 2007; Stone et al., 2002). Therefore, Arctic nesting geese may miss the rapid seasonal development because of late arrival relative to plant growth phenology at the breeding ground. The mismatches between arrival time at the breeding ground and the initiation of plant growth can affect the timing of optimal breeding conditions (Pearce-Higgins et al., 2005). Therefore, an accurate understanding of the timing of the spring migration of avian herbivores such as geese to both stopover and breeding sites with respect to the green wave of plant phenology might help to predict the consequences of future climate change on migration patterns on individuals and therefore also on populations.

Satellite imagery provides a potential tool for ecologists and conservation biologists to investigate vegetation productivity and phenology for large regions and long time-frames (Kerr and Ostrovsky, 2003; Pettorelli et al., 2005). The normalized difference vegetation index (NDVI) is a measure of the presence and vigor of green vegetation and is calculated from the near-infrared (NIR) and red reflectance that can be captured by satellite sensors (Myneni et al., 1995; Reed et al., 1994). Photosynthetically active green vegetation has a high NIR reflection and low red reflection resulting in a high NDVI. Because clouds may obstruct the visibility of the land cover, frequent imagery is required to obtain accurate information on temporal changes of vegetation growth. Due to the trade-off between spatial and temporal resolution, daily imaging of the same site is currently only feasible with a relatively coarse spatial resolution. The most commonly used sensors for long-term monitoring of seasonal changes of green vegetation include the Advanced Very High Resolution Radiometer (AVHRR) at $8 \mathrm{~km}$ resolution, the Satellite Pour I'Observation de le Terre-Vegetation (SPOT-VGT) at $1 \mathrm{~km}$ resolution, and the Moderate Resolution Imaging Spectroradiometer (MODIS) data set at $1 \mathrm{~km}$ resolution (Pettorelli et al., 2005).

Satellite-derived NDVI time series yield reasonable estimates of biomass (Skidmore and Ferwerda, 2008) and may also be used to infer vegetation quality, because the nutritional quality declines as vegetative biomass increases (Fryxell, 1991). Thus, NDVI time series have been used to link plant quality with herbivore habitat use (Hamel et al., 2009; Marshal et al., 2006; Mueller et al., 2008; Tveraa et al., 2013). In a study conducted by Doiron et al. (2013) on Bylot Island, Canada, NDVI temporal changes were related to the date of peak nitrogen concentration in above-ground graminoid plants (grasses and grass-like plants, rushes, sedges). Their results showed that the date when NDVI was halfway the seasonal minimum and maximum value was the best predictor for the date of peak nitrogen in graminoids. They indicated that this date constitutes an important phenological event for herbivores such as the greater snow goose, Anser caerulescens atlantica, which breeds in the Arctic tundra ecosystem.

NDVI time series have been used to improve our understanding of the movements of herbivores, and how they relate to the spatio-temporal variation in the forage characteristics of their environment. For instance, a powerful predictive migration model for the migratory zebra, Equus burchelli antiquorum, was developed using NDVI data to evaluate how their timing and pace of movement is affected by spatio-temporal changes in the environment (Bartlam-Brooks et al., 2013). Another example also showed that elephants tracked an intermediate value of NDVI in the Marsabit protected area in Kenya, corresponding to the "surfing the green wave" hypothesis (Bohrer et al., 2014).

For animal migration studies, NDVI time series have often been transformed into the green wave index (GWI), i.e. a normalized NDVI trajectory for each pixel with a ratio output, where $0 \%$ reflects the annual minimum and 100\% the annual maximum NDVI (Beck et al., 2008; White et al., 1997). The GWI has been successfully used to explain the seasonal movements of giant pandas, Ailuropoda melanoleuca, in relation to plant phenology (Beck et al., 2008). Moreover, using the GWI, Bischof et al. (2012) showed that ungulates can time their migration to either surf a wave of food availability (i.e. green wave) or jump ahead of the green wave as they move along the migration corridor. In addition to mammals, the migration of barnacle geese, Branta leucopsis, with respect to the vegetation phenology was successfully studied using the GWI index (Shariatinajafabadi et al., 2014).

An alternative parameter that may be used to test the green wave hypothesis is temperature, which is an important factor for plant phenology (Gordo and Sanz, 2009; Menzel et al., 2006). Plant phenology studies have traditionally used models based on variables, such as growing degree days (GDD), i.e. the sum of mean daily temperature above a certain temperature threshold (Wang, 1960). This measure is relevant for different phases of plant development (Cleland et al., 2007; Gordo and Sanz, 2010). Van Eerden et al. (2005) proposed to use the day at which GDD reaches $180^{\circ} \mathrm{C}$ as a definition of the start of spring (using a threshold of $0{ }^{\circ} \mathrm{C}$ and a starting date of 1st January). Furthermore, the rate of change in temperature acceleration (GDDjerk) could be another proxy for the onset of spring (Fitzjarrald et al., 2001; Van Wijk et al., 2012).

The GDD and day length were found to be accurate predictors for timing the migration of pink-footed geese, Anser brachyrhynchus (Bauer et al., 2008; Duriez et al., 2009). Van Wijk et al. (2012) compared three green wave indices (GDD $180^{\circ} \mathrm{C}$, GDDjerk, and date of snow melt) with variables related to the accumulated photoperiod (period between sunrise and sunset) and latitude to predict the arrival date of white-fronted geese, Anser albifrons, at stopover sites during their spring migration from the Netherlands to Russia. The arrival of white-fronted geese at stopover sites was predicted most accurately by the peak in GDDjerk (i.e. the highest acceleration of daily temperature per site) (Van Wijk et al., 2012). Kölzsch et al. (2014) used the same index to show how much the onset of spring is correlated across successive stopover sites, and if the timing of goose migration depends on this predictability of onset of spring between sites. Based on their results, if there is high predictability between the consecutive stopover sites, the geese closely follow the onset of spring during their migration.

Air temperatures, solar radiation and water are the most critical constraints to vegetation growth in different parts of the world (Churkina and Running, 1998; Nemani et al., 2003). The relationship between temperature or growing degree days with different phases of plant development, especially spring flush of plants, is well known (Cleland et al., 2007; Schwartz, 2003). For this reason, a number of studies could identify significant relationships between temperature and NDVI (Jia et al., 2003; Maselli et al., 1998).

NDVI is closely related to the amount of photosynthetically active radiation absorbed by vegetation canopies (Slayback et al., 2003). NDVI has been used as a direct measure of plant phenology to study the effect of seasonality in plant phenology on synchrony of herbivores reproduction (Loe et al., 2005). Therefore, plant phenology can be directly studied through NDVI, and not through its proxy' growing degree days (GDD) that is an indirect measure of plant development (Kerby and Post, 2013). Based on this 
assumption, we hypothesized that the timing of herbivorous waterfowl migration, with respect to the green wave phenology, would be predicted more accurately by GWI than GDDjerk. We examined this hypothesis for individual, GPS-tagged barnacle geese, Branta leucopsis, during their spring migration to sub-Arctic breeding sites via the stopover sites along the Baltic coast, on islands in the White Sea, and on the Kanin Peninsula (Eichhorn et al., 2006, 2009).

\section{Materials and methods}

\subsection{Satellite-derived green wave index (GWI)}

In this study, GWI was calculated from the MODIS 16-day composite NDVI dataset (MOD13A2) with a 1-km spatial resolution for the 4-year period of 2008-2011 (Beck et al., 2008; Huete et al., 2002). A single year contains 2316 -day composites. Before computing the GWI, two pre-processing steps were applied to the whole NDVI time series: (1) an estimate of the winter NDVI for any snowaffected pixel from October to February to reduce the effect of snow in high latitudes, using a method proposed by Beck et al. (2006), and (2) the Savitzky-Golay filter and double logistic function-fitting to reduce noise and maintain the integrity of the time series data (Beck et al., 2006; Chen et al., 2004; Jonsson et al., 2010). To calculate daily GWI values for each pixel, the $23 \mathrm{NDVI}$ image composites were interpolated to 365 daily images, and then normalized to cover the range of $0-100 \%$, where $0 \%$ corresponds to the annual pixel's minimum NDVI value and $100 \%$ to its annual maximum value (Beck et al., 2008; White et al., 1997). The 50\% GWI (intermediate stage of greenness) was taken to represent high forage quality for herbivores based on Doiron et al. (2013).

\subsection{Temperature acceleration (GDDjerk)}

The air temperature data were obtained from the global land data assimilation system (GLDAS), on a fixed grid of $0.25^{\circ}$ and at a 3-hour temporal resolution. Growing degree days (GDD) were calculated following the method proposed by McMaster and Wilhelm (1997) from $k=1$ January to 31 December:

$G D D=\sum T_{A V G, k}-T_{B A S E}$

where $T_{A V G, k}$ is the average temperature calculated from the daily maximum and minimum air temperature. $T_{B A S E}$ is the base temperature for plant growth and if $T_{A V G, k}<T_{B A S E}$, then $T_{A V G, k}=T_{B A S E}$ (Črepinšek et al., 2006). Following Van Wijk et al. (2012), the $T_{B A S E}$ at a given latitude was estimated as: $T_{B A S E}=(-0.25 \times$ latitude $)+13$. They derived the parameters for this equation from linear regression between a $T_{B A S E}$ of $0^{\circ} \mathrm{C}$ in the Netherlands $\left(52^{\circ} \mathrm{N}\right)$ (Lantinga, $1985)$ and a $T_{B A S E}$ of $-5^{\circ} \mathrm{C}$ in northern Russia $\left(72^{\circ} \mathrm{N}\right)$ (Botta et al., 2000).

The GDDjerk was derived from fitting a sigmoid function through the data points that plot the day $k$ against $G D D_{k}$ for each year. The third derivative of this sigmoid function is the GDDjerk (Van Wijk et al., 2012). For each pixel, the date of the first peak in GDDjerk was derived as a proxy for the start of spring.

\subsection{GPS tracking data}

A total of 15 female barnacle geese were equipped with $30 \mathrm{~g}$ solar GPS/ARGOS transmitters fixed on their backs with a nylon harness (Solar GPS 100 PTT; PTT-platform transmitter terminal; Microwave Telemetry, Inc., Columbia, MD, USA). These birds were tracked from their overwintering sites in the Netherlands to their breeding ground on the Arctic coast of Russia during 2008-2011. The transmitters were programmed to record GPS locations four
Table 1

Tag/Bird ID, number of stopover sites, and years of tracking of 12 barnacle geese breeding in the Russian Arctic.

\begin{tabular}{lrr}
\hline Bird ID & No. of stopover sites & \multicolumn{1}{l}{ Total } \\
\hline 78033 & 3 & $2009-2011$ \\
78034 & 4 & $2009-2011$ \\
78035 & 3 & $2009-2011$ \\
78036 & 3 & $2009-2010$ \\
78037 & 2 & 2009 \\
78039 & 7 & $2009-2011$ \\
78041 & 6 & $2008-2010$ \\
78043 & 10 & $2008-2010$ \\
78044 & 10 & $2008-2010$ \\
78045 & 4 & 2008 \\
78046 & 2 & $2008-2009$ \\
78047 & 10 & $2008-2010$ \\
\hline
\end{tabular}

(or five) times per day (Appendix I) (for details ARGOS/CLS, 2011; Ens et al., 2008).

Of the tagged geese, 12 yielded at least one full spring migration, 10 of which were tracked for more than one year, resulting in a total of 33 GPS spring migration tracks. Three incomplete migrations were removed from the analysis, leaving 30 full data tracks (Table 1). The risk of pseudo-replication was considered in this study, and the methods regarding how it is dealt with is described later. The barnacle geese tracking data can be viewed at movebank.org: "Migration timing in barnacle geese (Barents Sea), data from Kölzsch et al. and Shariatinajafabadi et al., 2014", DOI: 10.5441/001/1.ps244r11".

\subsection{Delineation of stopover, and breeding sites}

The Russian population of barnacle geese winters along the Wadden Sea coast of Denmark, Germany and Netherlands. In April/May, the geese leave the spring fattening area of the Wadden Sea and move via stopover sites along the Baltic Sea coast, most notably in western Estonia and on the Swedish Island of Gotland, the White Sea and Kanin Peninsula to their breeding area on the Barents Sea coast. The breeding areas of this population were formerly confined to the islands of Novaya Zemlya and Vaygach, but it is now found breeding from the Kanin Peninsula in the west to Vaygach and Novaya Zemlya in the east, both on islands and on the Russian mainland (Madsen et al., 1999).

The stopover sites for each individual goose were identified as sites where the birds stopped for longer than $48 \mathrm{~h}$ within a radius of $30 \mathrm{~km}$ that allows a maximum of one outlier position (Van Wijk et al., 2012). Sites used for 7-26 days within a radius of $30 \mathrm{~km}$ in the second half of June were marked as breeding sites. In total, 64 stopover sites and 30 breeding sites were recognized along the Russian flyway for the 12 barnacle geese from 2008 to 2011 (Fig. 1).

\subsection{Statistical analysis}

To avoid pseudo-replication caused by sequential observations of individual goose a linear mixed-effect model was used with a fixed effect for the dates of 50\% GWI or peak GDDjerk. The individual identity and tracking year were considered as random effects. The models were fitted by maximum likelihood (ML) estimation methods using the linear mixed effect regression function (lmer) of the lme4 package (Bates et al., 2014) in the R statistical software version 3.1.2 ( $\mathrm{R}$ Core Team, 2014).

We calculated the proportion of total variance accounted for each random effect, by dividing the random effect's variance (between-group variance) by the total variance (betweengroup variance + within-group variance) (Lessells and Boag, 1987; Nakagawa and Schielzeth, 2010). The $t$ test was used to examine the significance of the fixed effects (Bolker et al., 2009), and 

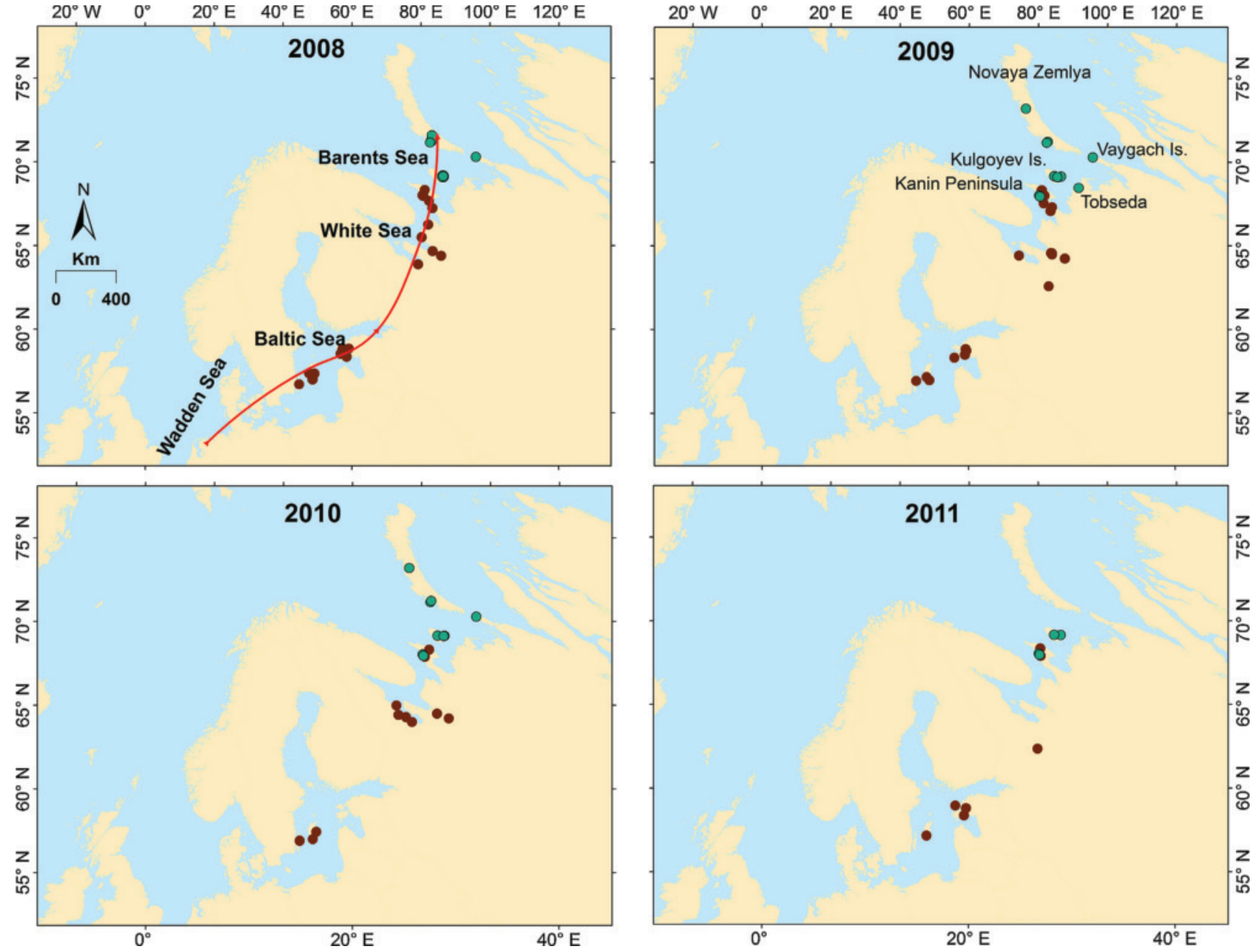

Fig. 1. Stopover and breeding sites of Russian barnacle geese. The red arrow shows the spring migration route of Russian barnacle geese from their wintering to their breeding sites. The brown dots indicate the stopover sites and the green dots the breeding sites of the 12 barnacle geese tracked from 2008 to 2011 . All individual barnacle geese that have been tracked more than one year, occupied the same breeding site in different years. The Kanin Peninsula was occupied by individuals with IDs 78033 (2009-2011) and 78035 (2009-2011). The Kulgoyev island was occupied by IDs 78034 (2009-2011), 78039 (2009-2011), 78043 (2008-2010) and 78046 (2008-2009). The Novaya Zemlya was occupied by IDs 78036 (2009-2010), 78047 (2008-2010), and 78045 (2008). The Vaygach island was occupied by ID 78044 (2008-2010), and Tobseda was occupied by ID 78037 (2009). The only exception was ID 78041 that occupied Novaya Zemlya in 2008 and 2010, but Kulgoyev island in 2009.(For interpretation of the references to color in this figure legend, the reader is referred to the web version of this article.)

likelihood ratio test was used to examine the significance of the random effects (Pinheiro and Bates, 2009). If the variance of a random effect was relatively small, we removed the random effect from the model (Mathworks, 2013). The Akaike Information Criterion (AIC) and Bayesian Information Criterion (BIC) were used to compare the fitness of the models, and the models with lower AIC and BIC were preferred.

In order to evaluate the predictive performance of the GWI and GDDjerk models, we used cross-validation with the leave-one-out procedure. In this method, a calibration set of $n-1$ samples is used to predict the sample that was left out, and this procedure is repeated $n$ times. The prediction success of the GWI and GDDjerk models was evaluated on predicted and observed arrival dates, using the cross-validated root mean square deviation $\left(\mathrm{RMSD}_{c v}\right)$, and the cross-validated coefficient of determination $\left(R^{2} c v\right)$. The more accurate model is the model with higher $R^{2} c v$ and lower $\operatorname{RMSD}_{c y}$.

To graphically compare the observed with the predicted arrival dates using GWI and GDDjerk models, they were plotted in a Bland-Altman plot with the $95 \%$ limits of agreement (i.e. the $95 \%$ confidence interval) (Bland and Altman, 1995). All of the statistical analyses were repeated once for arrival date to the stopover sites, and once for arrival date to the breeding sites.

\section{Results}

\subsection{Arrival date at the stopover sites}

The obtained results for the GWI mixed-effect model showed that the residual variance estimate $(\hat{\sigma}=30.69)$ was larger than the random effect variance estimate of individual identity $(\hat{\sigma}=$ 0 ), and the random effect variance estimate of a tracking year $(\hat{\sigma}=2.60)$. In other words, the random effect for individual identity accounted for $0 \%$, and the random effect of a tracking year accounted for only $8 \%$ of the total variance of random effect. These relatively low variance estimates of random effects indicate that the level of between-group variability is low and that random effects can safely be eliminated from the model (Mathworks, 2013). We therefore removed the random effect from GWI model, and used ordinary least square (OLS) regression with only a fixed effect for the analysis. The results of OLS showed that there are significant relationships between the arrival dates at the stopover sites and the dates of $50 \% \mathrm{GWI}\left(R^{2}=0.69, p<0.001, n=64\right)$ (Table 2$)$.

Using the mixed-effect model, we found a significant linear relationship between the arrival date at the stopover site and the date of peak GDDjerk (slope on in scale for GDDjerk $=0.21 \pm 0.02$; $t_{63}=9.46, p$-value $<0.001$ ) (Table 2). Inclusion of year and 
Table 2

Effects of the 50\% GWI and the peak of GDDjerk on barnacle goose arrival dates at the stopovers sites. Results are from ordinary least square (OLS) for GWI and linear mix effect for GDDjerk models, conducted for 12 barnacle geese which were tracked from 2008 to 2011.

\begin{tabular}{|c|c|c|c|c|c|c|}
\hline Model & Fixed effect & Parameter \pm SE & $t$-value & $p$-value & $-95 \% \mathrm{CI}$ & $+95 \% \mathrm{CI}$ \\
\hline \multirow[t]{2}{*}{ GWI } & Intercept & $21 \pm 9.76$ & 2.15 & $<0.05$ & 1.49 & 40.52 \\
\hline & GWI & $0.83 \pm 0.06$ & 11.99 & $<0.001$ & 0.70 & 0.98 \\
\hline \multirow[t]{5}{*}{ GDDjerk } & Intercept & $111.94 \pm 3.67$ & 19.07 & $<0.001$ & 103.88 & 119.44 \\
\hline & GDDjerk & $0.21 \pm 0.02$ & 9.46 & $<0.001$ & 0.17 & 0.26 \\
\hline & Random effect & Variance & $\chi^{2}$ & $p$-value & & \\
\hline & ID & 10.9 & 13.83 & $<0.01$ & & \\
\hline & Year & 18.88 & 7.84 & $<0.001$ & & \\
\hline
\end{tabular}

CI - confidence interval, SE - standard error, $\chi^{2}-$ Chi-square.

individual identity as random intercepts significantly improved the fit of GDDjerk model for arrival time $\left(\chi^{2}=13.83, p<0.01\right.$ for ID, and $\chi^{2}=7.84, p<0.001$ for year, Table 2$)$. Individual identity and year explained $17 \%$ and $29 \%$ of the residual variance in arrival date respectively, not accounted by the GDDjerk (fix effect). This suggests that there were a repeatable inter-individual and between year difference among barnacle geese in the arrival date to the stopover sites based on the peak of GDDjerk.

In the next step, the cross validated $R^{2}$ and RMSD were calculated for both GWI and GDDjerk models. As shown in Fig. 2, the GWI is a more accurate index for predicting the arrival date at stopover sites $\left(R_{c v}^{2}=0.68, \mathrm{RMSD}_{c v}=5.9\right)$ than GDDjerk $\left(R^{2} c v=0.45\right.$, $\operatorname{RMSD}_{c v}=7.79$ ). Using the GWI model, the data points (observed and predicted arrivals) are distributed around the 1:1 line. Instead, the data points for the GDDjerk model are dispersed, and are only close to the 1:1 line between DOY (i.e. day of the year) 140 and 160 (late May to early June), when birds arrived at higher latitudes.

The Bland-Altman plot (Fig. 3) for the GWI model shows a uniform distribution and relatively good agreement between the observed and predicted arrival dates along the migration route. But the observed and predicted arrival dates using the GDDjerk model were not evenly distributed in this plot, and some data exceeded the $95 \%$ limit of agreement. For the GWI model the 95\% limits of agreement in these plots were narrower than the GDDjerk model. This indicates that the difference between observed and predicted arrival dates using the GWI model is smaller than with GDDjerk model.

As it can be observed from the Bland-Altman plot, for the GDDjerk model the points between DOYs 100 and 140 (arrival date to the lower latitude) were more dispersed than between DOYs 140 and 160 (arrival dates to the higher latitude). However, this was not the case for the GWI model, as the points were evenly distributed from lower to higher latitude. To explore the effect of latitude further, we performed a Pearson's correlation analysis between the absolute residuals values and distance to the breeding site. The results showed that for the GDDjerk model, there was a significant positive correlation between the residual and the distance (Pearson correlation coefficient $=0.32, p<0.01)$. This indicates that for the GDDjerk model the difference between observed and predicted arrival time becomes less when birds are approaching the breeding site. Unlike for the GDDjerk model, the correlation was not significant for the GWI model (Pearson correlation coefficient $=-0.01$, $p=0.89$ ).

To illustrate how barnacle geese follow the GWI and GDDjerk during their northward migration, both indices were mapped for 2010, together with the barnacle geese stopover sites for the corresponding time periods (Fig. 4). The arrival dates of the barnacle geese coincided well with the middle range of GWI (GWI $=50 \%)$, but the geese did not follow the peak of GDDjerk during their northward migration. For example, one goose arrived at the White Sea
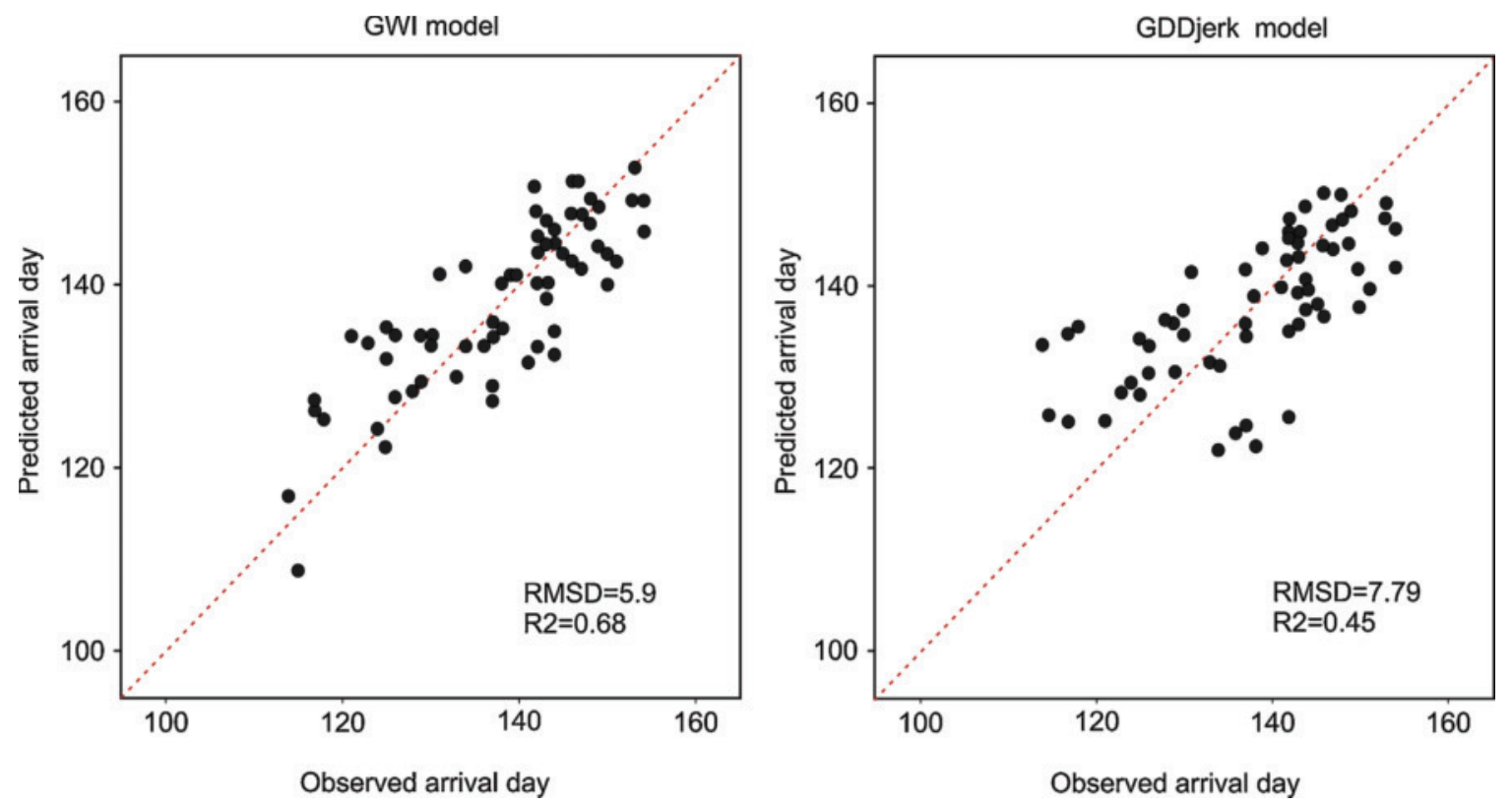

Fig. 2. Cross validation results for stopover sites. The relationship between observed and predicted arrival dates of barnacle geese at the stopover sites for the GWI and GDDjerk indices, using linear regression models. Note that the values of $R^{2}$ and RMSD are cross-validated. The red dotted line is the $1: 1$ line.(For interpretation of the references to color in this figure legend, the reader is referred to the web version of this article.) 
GWI model

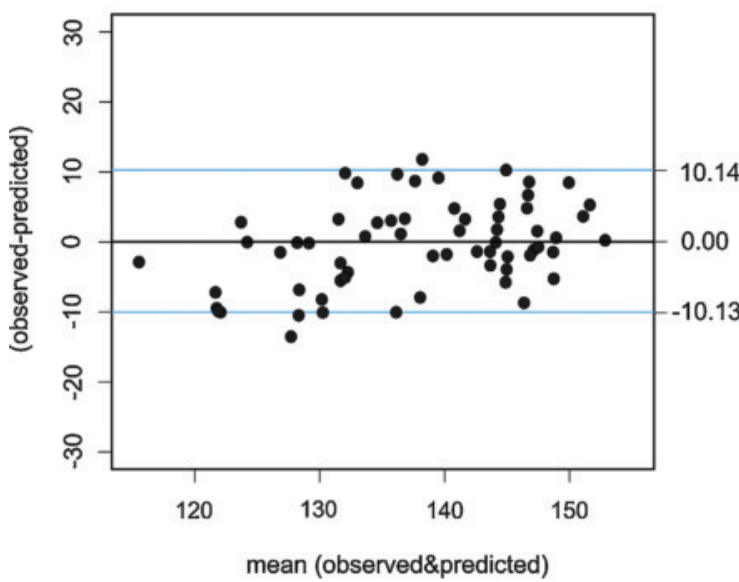

GDDjerk model

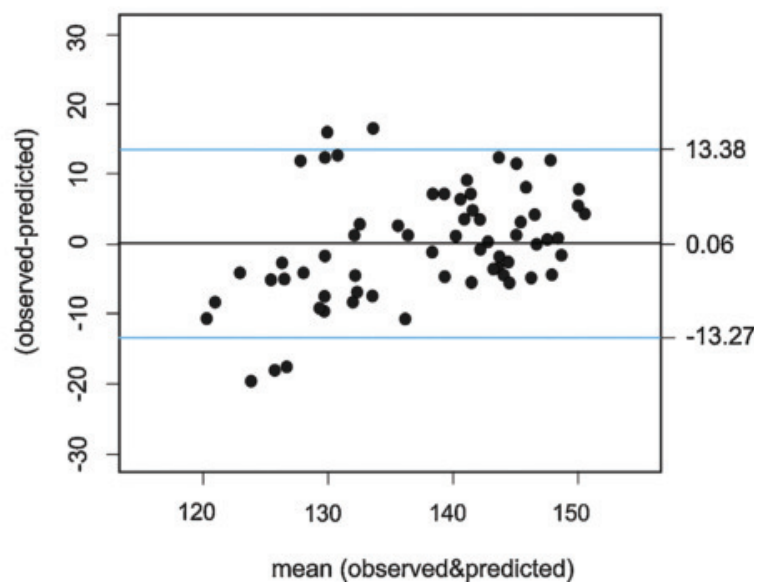

Fig. 3. Bland-Altman plots for stopover sites. Bland-Altman plots of the difference between the observed and predicted arrival dates at the stopover sites for the GWI and GDDjerk models. The blue lines represent $95 \%$ limits of agreement.(For interpretation of the references to color in this figure legend, the reader is referred to the web version of this article.)

on 24th May, when GWI was 50\%, but the peak of GDDjerk at this site occurred on 17th May almost one week before the bird arrived (Fig. 4).

\subsection{Arrival date at the breeding site}

Significant linear relationships exist between arrival date at the breeding site with both the date of $50 \%$ GWI (slope on in scale for $\mathrm{GWI}=0.50 \pm 0.07, t_{29}=6.77$ ), and the date of peak GDDjerk (slope on in scale for GDDjerk $=0.34 \pm 0.10, t_{29}=3.21$ ) (Table 3 ). Arrival date to the breeding site exhibited significant repeatable inter-individual and between-year variation as inclusion of the individual identity and year significantly improved the fit of the GWI $\left(\chi^{2}=5.45, p<0.05\right.$ for ID, and $\chi^{2}=11.64, p<0.000$ for year; Table 3$)$, and the GDDjerk models $\left(\chi^{2}=6.35, p<0.05\right.$ for ID, and $\chi^{2}=17.40, p<0.000$ for year; Table 3$)$. Identity and year explained $28 \%$ and $40 \%$, in the GWI and $20 \%$ and $58 \%$ in the GDDjerk model, of the variance in arrival date not accounted by the fixed effects, respectively. Moreover, the comparison between the GWI and GDDjerk models using AIC and BIC values showed an increase in both when replacing the GWI with GDDjerk as a fix effect in the mixed model (Table 4).
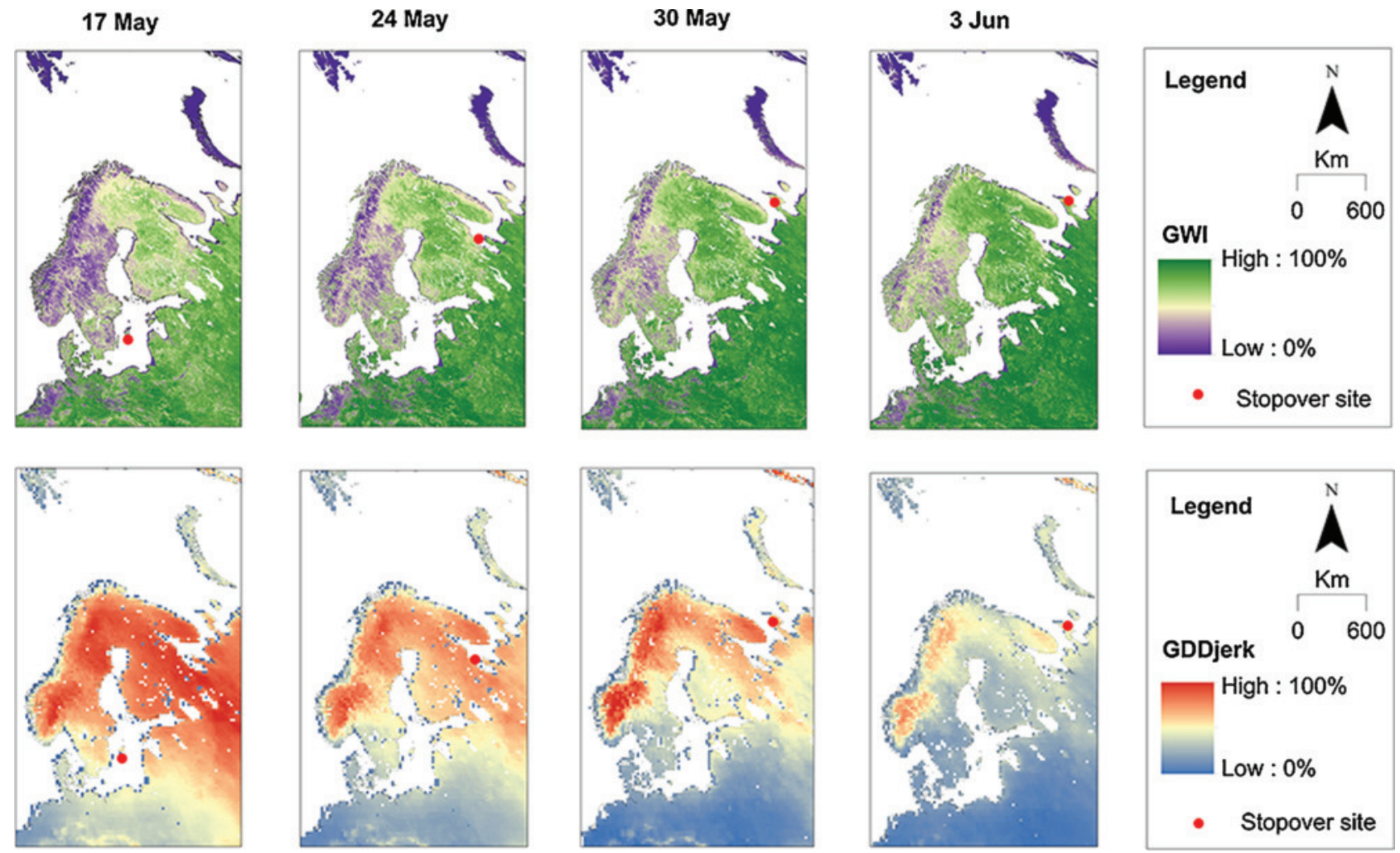

Fig. 4. The northward spring migration of barnacle geese in relation to the green wave. Example to illustrate the northward migration of one barnacle goose (ID: 78047) in 2010 in relation to the GWI and GDDjerk indices. The arrival date at each stopover site is shown above the images. Note that the decrease in GDDjerk indicates a slower rate of warming up as spring proceeds. 
Table 3

Effects of the 50\% GWI and the peak of GDDjerk on barnacle geese arrival time at the breeding sites. Results are from linear mixed effect, conducted for 12 barnacle geese which were tracked from 2008 to 2011

\begin{tabular}{|c|c|c|c|c|c|c|}
\hline Model & Fixed effect & Parameter \pm SE & $t$-value & $p$-value & $-95 \% \mathrm{CI}$ & $+95 \% \mathrm{CI}$ \\
\hline \multirow[t]{5}{*}{ GWI } & Intercept & $74.98 \pm 11.96$ & 6.26 & $<0.000$ & 50.36 & 99.90 \\
\hline & GWI & $0.50 \pm 0.07$ & 6.77 & $<0.000$ & 0.35 & 0.66 \\
\hline & Random effect & Variance & $\chi^{2}$ & $p$-value & & \\
\hline & ID & 4.96 & 5.45 & $<0.05$ & & \\
\hline & Year & 7.09 & 11.64 & $<0.000$ & & \\
\hline \multirow[t]{6}{*}{ GDDjerk } & Fixed effect & Parameter $\pm \mathbf{S E}$ & $t$-value & $p$-value & $-95 \%$ CI & $+95 \% \mathrm{CI}$ \\
\hline & Intercept & $103.35 \pm 16.37$ & 6.31 & $<0.000$ & 70.16 & 137.06 \\
\hline & GDDjerk & $0.34 \pm 0.10$ & 3.21 & $<0.01$ & 0.12 & 0.55 \\
\hline & Random effect & Variance & $\chi^{2}$ & $p$-value & & \\
\hline & ID & 8.88 & 6.35 & $<0.05$ & & \\
\hline & Year & 24.78 & 17.40 & $<0.000$ & & \\
\hline
\end{tabular}

CI - confidence interval, SE - standard error, $\chi^{2}-$ Chi-square.
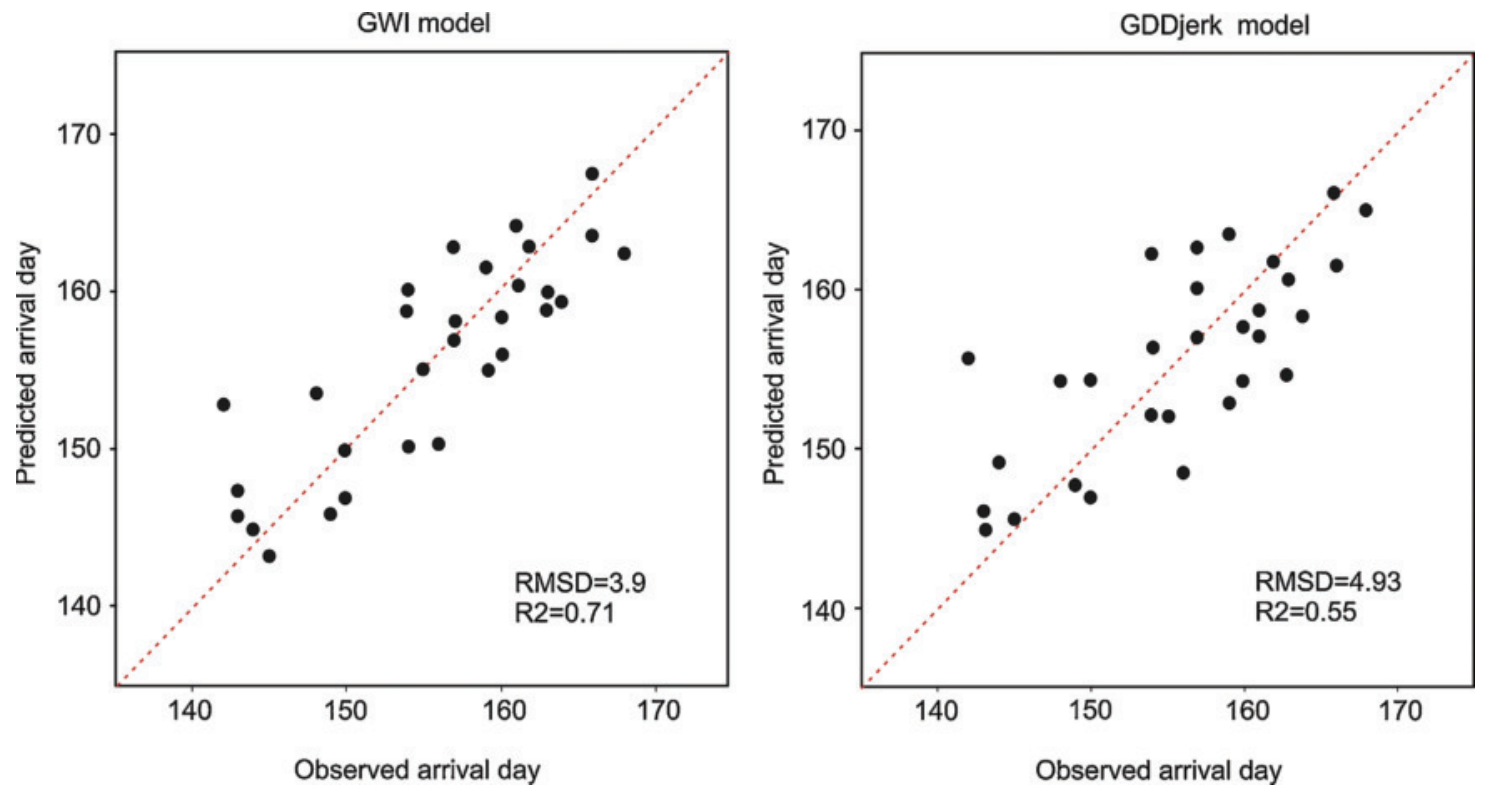

Fig. 5. Cross validation results for breeding sites. The relationship between observed and predicted arrival dates of barnacle geese at the breeding sites for the GWI and GDDjerk indices, using linear regression models. Note that the values of $R^{2}$ and RMSD are cross-validated. The red dotted line is the $1: 1$ line.(For interpretation of the references to color in this figure legend, the reader is referred to the web version of this article.)

GWI model

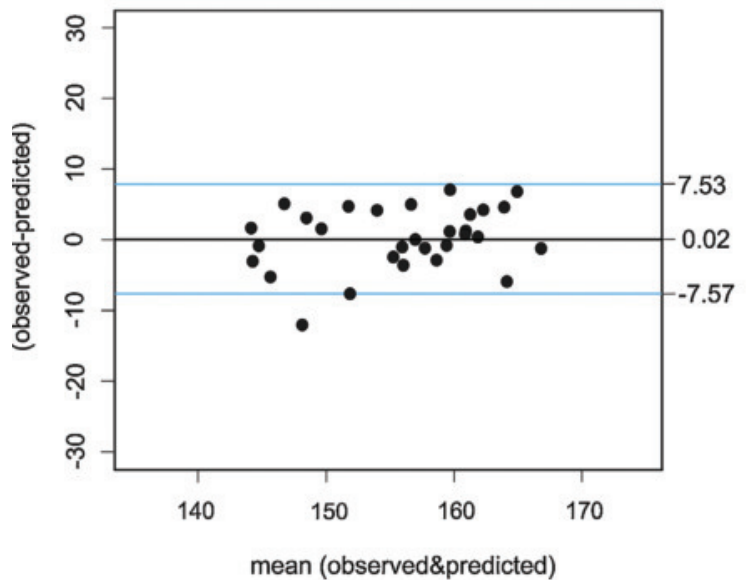

GDDjerk model

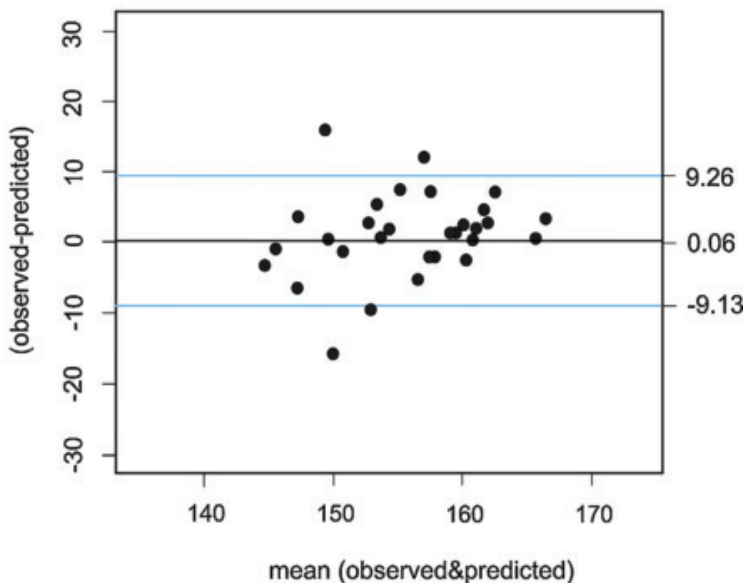

Fig. 6. Bland-Altman plots for breeding sites. Bland-Altman plots of the difference between the observed and predicted arrival dates at the breeding sites for the GWI and GDDjerk models. The blue lines represent 95\% limits of agreement.(For interpretation of the references to color in this figure legend, the reader is referred to the web version of this article.) 
Table 4

Model comparison of GWI and GDDjerk models. The AIC and BIC are smallest for the GWI model.

\begin{tabular}{llll}
\hline Model & d.f. & AIC & BIC \\
\hline GWI & 5 & 167.74 & 174.75 \\
GDDjerk & 5 & 186.16 & 193.17 \\
\hline
\end{tabular}

Validations of the two models were done utilizing crossvalidation. The cross validated results in Fig. 5 demonstrate that the arrival date to the breeding site is predicted more accurately by the GWI $\left(R_{c v}^{2}=0.71, \operatorname{RMSD}_{c v}=3.9\right)$ than the GDDjerk model $\left(R_{c v}^{2}=0.55, R^{2} S_{c v}=4.93\right)$. The Bland-Altman plots (Fig. 6) show that the observed and predicted arrival dates using GWI models are evenly distributed, however, this was not the case for GDDjerk model. Moreover, the difference between observed and predicted arrival dates using the GWI model is smaller than the GDDjerk model (Fig. 6).

\section{Discussion}

Our results suggest that the satellite-derived green wave index (GWI) is a more reliable index to predict barnacle goose arrival time at both stopover and breeding sites than the temperature-derived index (GDDjerk). Although the arrival dates of the individual geese were significantly related to both green wave indices, the crossvalidated result revealed a better fit between the observed and predicted arrival dates obtained from the GWI model than from the GDDjerk model.

Moreover, our results indicate that unlike the GWI model, the GDDjerk model was sensitive to latitude. The prediction power of the GDDjerk model at the stopover sites was more accurate at the high latitudes. Moreover, the difference between the RMSD ${ }_{c v}$ of the two models became smaller in breeding sites. This can be explained by the longer growing season and higher optimum temperature for the shoot growth of plants in temperate areas (Chapin, 1983). In contrast to the temperate region, the growing season in the high Arctic environment is short and the plant growth is more rapid in relation to favorable temperatures (Beck et al., 2006; Bliss, 1962, 1971). It also was shown by Van Wijk et al. (2012) that GDDjerk is more peaked at higher latitudes. Therefore, the time interval between the date of peak GDDjerk and onset of plant growth is reduced at higher latitudes which may cause a smaller gap between peak GDDjerk and the geese arrival date in this area.

Overtaking the successively delayed spring flush of plants en route is an important migratory phenomenon for the Arctic-nesting geese as many geese are at least partly capital breeders, meaning that they rely on the amount of fat accumulated and energy stored from their different stopovers for successful breeding (Gauthier et al., 2003; Hahn et al., 2011; Hübner, 2006). Therefore, the northward spring migration of geese has to commence at the right time and they should be able to follow the green wave of plant phenology based on green wave hypothesis (Owen, 1980). The approximate match between onset of spring associated with temperature sum and goose migration could support the green wave hypothesis (Van Wijk et al., 2012). Environmental (temperature sum, food resources) and energy cues have been recognized as the most accurate predictors for when migratory geese decide to depart from a stopover site (Duriez et al., 2009). Moreover, Van der Graaf (2006) found a correlation between the accumulated spring temperatures (GDD) at successive stopover sites for the barnacle geese that breed in Russia. In other study, Kölzsch et al. (2014) showed that a higher predictability of climatic conditions and the onset of spring at consecutive stopover sites was associated with a closer match of goose arrival and the green wave during their spring migration. Although the above cited studies used temperature sum as a proxy for the local onset or progression of spring, the results of our study indicate that a more direct measure (such as GWI) should be preferred.

For consecutive stopovers lacking a strong correlation between their climatic conditions, studies showed that birds were unable to time their migration optimally (Kölzsch et al., 2014; Tombre et al., 2008). This was for example the case for the migration from the Baltic to the White Sea area (Kölzsch et al., 2014; Van der Graaf, 2006). Despite the low predictability of climatic conditions between these two areas, our results showed that the GWI model worked well in predicting goose arrival dates in these two regions. This could be explained by the fact that birds use other time-related cues, such as day length, to time their departure from the Baltic Sea to move on to the White Sea, as suggested by Van der Graaf (2006). However, with climate change and an earlier onset of spring (IPCC, 2007), barnacle geese may still be able to follow the green wave, i.e. the date of $50 \%$ GWI from the Baltic Sea to the White Sea. This is because of the fact that species can adjust their behavior to climate change through phenotypic plasticity (Muñoz et al., 2015).

The between-year variations in bird arrival dates can be due to environmental conditions determined by climate (Žalakevicius, 1997). However, bird spring arrival predominantly depends on food availability which depends upon temperature (Žalakevicius, 1997). An increase of monthly air temperature during the growing season (May-October) was observed from 2008 to 2010 in western Europe (Tullus et al., 2012), and spring warming is known to cause increased photosynthetic activity and vegetation growth for northern high latitudes (Myneni et al., 1997). Therefore the time interval between peak GDDjerk and the geese arrival at the consecutive stopover sites was smaller than for colder years with a later onset of spring. Unlike the GDDjerk model, we did not find any repeatable difference in arrival date to the stopover site among individuals and years with respect to the GWI index. In other words, the fixed effect of GWI alone explained most variance in the arrival date of barnacles at the stopover site.

Compared to the stopover sites, we observed relatively high inter-individual and between-year repeatability in arrival date to the breeding sites using both models. This might be because geese arrival on the breeding site is a trade-off between benefitting from early arrival, and staying longer in staging sites resulting in more accumulation of body fat (Prop et al., 2003). Thus, the individuals that are unable to accumulate large body store, try to arrive earlier to the breeding sites to increase the survival rate of the off-spring and so increase their reproduction chance (Prop et al., 2003).

Repeatable arrival dates to the breeding site have been shown for other migratory birds such as snow geese (Anser caerulescens) (Bety et al., 2004) and black-tailed godwits (Limosa l. limosa) (Lourenço et al., 2011). Several studies have indicated that some of the migratory birds behavior such as migration timing may have a genetic basis (Berthold et al., 2001; Pulido and Berthold, 2003). This genetic basis for migration timing was also suggested for snow geese (Bety et al., 2004) and black-tailed godwits (Lourenço et al., 2011), and may consequently also explain between-individual barnacle geese's variation in migration timing. Moreover, part of the observed repeatability might be phenotype plasticity (i.e. an environmentally based change in the phenotype) that lead to adaptation to the environmental condition (Teplitsky et al., 2008).

\section{Conclusion}

Our results revealed that a satellite-based index that reflects the relative greenness of the vegetation (i.e. GWI) more accurately predicts the arrival dates of barnacle geese at stopover and breeding sites than a temperature-based index (i.e. GDDjerk). Moreover, we demonstrated that the GWI is not sensitive to latitude, and therefore is a reliable green wave index to predict the timing of spring 
migration of avian herbivores. The variation of land-surface plant phenology can be reasonably reflected by NDVI, since it is related to the amount of photosynthetically active radiation absorbed by green vegetation (Slayback et al., 2003). Thus, any variability of plant phenology and its effect on avian herbivore migration phenology can now be investigated directly using GWI and not through vegetation proxy' temperature. This shows the importance of the GWI index in studying migratory avian herbivores' movements that are influenced by spatio-temporal changes in the environment. Hence, our work highlights the use and importance of remote sensing data and the indices derived from it for animal migration studies.

\section{Acknowledgements}

This research received financial support from the EU Erasmus Mundus External Cooperation Window (EM8) Action 2 project, http://www.erasmusmundus8.net/ (project number 10438223). The Russian barnacle goose data were provided by FlySafe, a project initiated by the Integrated Applications Promotion (IAP) Programme of the European Space Agency. The study was carried out from 2007 onwards as cooperation between the Institute of Avian Research, the Dutch Centre of Field Ornithology (Sovon), and the University of Amsterdam. The project is facilitated by the infrastructure for e-Science, developed with the support of the NLeSC (http://www.esciencecenter.com/) and LifeWatch, and carried out on the Dutch national e-infrastructure with the support of SURF Foundation (cf. www.uva-bits.nl). In order to catch and fix transmitters on barnacle geese, we obtained a license under the Netherlands' Flora and Fauna Act (number FF75A/2007/056) and approval from the Dutch Ethical Committee (under protocol number CL 0703). A license to conduct this study in the Natura2000 area "Waddenzee" was obtained from the Province of Friesland (number 00692701). We thank Willem Nieuwenhuis for his help with the programming and Jackie Senior for editing the final version of the manuscript.

\section{Appendix I.}

For each individual GPS PTT information about the number by which it is identified (PTT ID), the weight in $\mathrm{g}$, and the duty cycle has been specified. The "duty cycle" indicates the hour of the day (local time) at which the PTT should take a GPS fix (if this includes a fix during midnight, this is indicated with a 0 at the start).

\begin{tabular}{lll}
\hline Bird ID & Weight & Duty cycle \\
\hline 78033 & $30 \mathrm{~g}$ & $0,8,11,14,17$ \\
78034 & $30 \mathrm{~g}$ & $0,8,11,14,17$ \\
78035 & $30 \mathrm{~g}$ & $0,8,11,14,17$ \\
78036 & $30 \mathrm{~g}$ & $0,8,11,14,17$ \\
78037 & $30 \mathrm{~g}$ & $0,8,11,14,17$ \\
78039 & $30 \mathrm{~g}$ & $0,8,11,14,17$ \\
78041 & $30 \mathrm{~g}$ & $8,11,14,17$ \\
78043 & $30 \mathrm{~g}$ & $8,11,14,17$ \\
78044 & $30 \mathrm{~g}$ & $8,11,14,17$ \\
78045 & $30 \mathrm{~g}$ & $8,11,14,17$ \\
78046 & $30 \mathrm{~g}$ & $8,11,14,17$ \\
78047 & $30 \mathrm{~g}$ & $8,11,14,17$ \\
\hline
\end{tabular}

\section{References}

ARGOS/CLS, 2011. Argos User's Manual.

Bartlam-Brooks, H.L.A., Beck, P.S.A., Bohrer, G., Harris, S., 2013. In search of greener pastures: using satellite images to predict the effects of environmental change on zebra migration. J. Geophys. Res. Biogeosci. 118, 1427-1437.

Bates, D., Eigen, C., Rcpp, L., 2014. Package 'Ime4'

Bauer, S., Gienapp, P., Madsen, J., 2008. The relevance of environmental conditions for departure decision changes en route in migrating geese. Ecology 89, 1953-1960.
Beck, P.S.A., Atzberger, C., Høgda, K.A., Johansen, B., Skidmore, A.K., 2006. Improved monitoring of vegetation dynamics at very high latitudes: a new method using MODIS NDVI. Remote Sens. Environ. 100, 321-334.

Beck, P.S.A., Wang, T.J., Skidmore, A.K., Liu, X.H., 2008. Displaying remotely sensed vegetation dynamics along natural gradients for ecological studies. Int. J. Remote Sens. 29, 4277-4283.

Berthold, P., Bauer, H.-G., Westhead, V., 2001. Bird Migration: A General Survey Oxford University Press, Oxford.

Bety, J., Giroux, J.F., Gauthier, G., 2004. Individual variation in timing of migration: causes and reproductive consequences in greater snow geese (Anser caerulescens atlanticus). Behav. Ecol. Sociobiol. 57, 1-8.

Bischof, R., Loe, L.E., Meisingset, E.L., Zimmermann, B., Van Moorter, B., Mysterud, A. 2012. A migratory northern ungulate in the pursuit of spring: jumping or surfing the green wave? Am. Nat. 180, 407-424.

Bland, J.M., Altman, D.G., 1995. Comparing methods of measurement: why plotting difference against standard method is misleading. Lancet 346, 1085-1087.

Bliss, L., 1962. Adaptations of arctic and alpine plants to environmental conditions. Arctic 15, 117-144.

Bliss, L.C. 1971. Arctic and alpine plant life cycles. Annu. Rev. Ecol. Syst. 2, 405-438.

Bohrer, G., Beck, P.S., Ngene, S.M., Skidmore, A.K., Douglas-Hamilton, I., 2014. Elephant movement closely tracks precipitation-driven vegetation dynamics in a Kenyan forest-savanna landscape. Mov. Ecol. 2, 2.

Bolker, B.M., Brooks, M.E., Clark, C.J., Geange, S.W., Poulsen, J.R., Stevens, M.H.H. White, J.-S.S., 2009. Generalized linear mixed models: a practical guide for ecology and evolution. Trends Ecol. Evol. 24, 127-135.

Botta, A., Viovy, N., Ciais, P., Friedlingstein, P., Monfray, P., 2000. A global prognostic scheme of leaf onset using satellite data. Glob. Change Biol. 6, 709-725.

Chapin III, F., 1983. Direct and indirect effects of temperature on arctic plants. Polar Biol. 2, 47-52.

Chen, J., Jonsson, P., Tamura, M., Gu, Z.H., Matsushita, B., Eklundh, L., 2004. A simple method for reconstructing a high-quality NDVI time-series data set based on the Savitzky-Golay filter. Remote Sens. Environ. 91, 332-344.

Churkina, G., Running, S.W., 1998. Contrasting climatic controls on the estimated productivity of global terrestrial biomes. Ecosystems 1, 206-215.

Cleland, E.E., Chuine, I., Menzel, A., Mooney, H.A., Schwartz, M.D., 2007. Shifting plant phenology in response to global change. Trends Ecol. Evol. 22, 357-365.

Črepinšek, Z., Kajfež-Bogataj, L., Bergant, K., 2006. Modelling of weather variability effect on fitophenology. Ecol. Model. 194, 256-265.

Doiron, M., Legagneux, P., Gauthier, G., Levesque, E., 2013. Broad-scale satellite normalized difference vegetation index data predict plant biomass and peak date of nitrogen concentration in Arctic tundra vegetation. Appl. Veg. Sci. 16, 343-351.

Duriez, O., Bauer, S., Destin, A., Madsen, J., Nolet, B.A., Stillman, R.A., Klaassen, M., 2009. What decision rules might pink-footed geese use to depart on migration? An individual-based model. Behav. Ecol. 20, 560-569.

Eichhorn, G., Afanasyev, V., Drent, R.H., van der Jeugd, H.P., 2006. Spring stopover routines in Russian Barnacle Geese Branta leucopsis tracked by resightings and geolocation. Ardea 94, 667-678.

Eichhorn, G., Drent, R.H., Stahl, J., Leito, A., Alerstam, T., 2009. Skipping the Baltic: the emergence of a dichotomy of alternative spring migration strategies in Russian barnacle geese. J. Anim. Ecol. 78, 63-72.

Ens, B.J., Bairlein, F., Camphuysen, C.J., de Boer, R., Exo, K.M., Gallego, N., Hoye, B., Klaassen, R., Oosterbeek, K., Shamoun-Baranes, J., Van der Jeugd, H., Van Gasteren, H., 2008. Tracking of Individual Birds. Report on WP 3230 (Bird Tracking Sensor Characterization) and WP 4130 (Sensor Adaptation and Calibration for Bird Tracking System) of the FlySafe Basic Activities Project. SOVON-onderzoeksrapport 2008/10.SOVON Vogelonderzoek Nederland, BeekUbbergen, The Netherlands.

Fitzjarrald, D.R., Acevedo, O.C., Moore, K.E., 2001. Climatic consequences of leaf presence in the eastern United States. J. Clim. 14, 598-614.

Fryxell, J.M., 1991. Forage quality and aggregation by large herbivores. Am. Nat. 138, $478-498$.

Gauthier, G., Bêty, J., Hobson, K.A., 2003. Are greater snow geese capital breeders? New evidence from a stable-isotope model. Ecology 84, 3250-3264.

Gordo, O., Sanz, J.J., 2009. Long-term temporal changes of plant phenology in the Western Mediterranean. Glob. Change Biol. 15, 1930-1948.

Gordo, O., Sanz, J.J., 2010. Impact of climate change on plant phenology in Mediterranean ecosystems. Glob. Change Biol. 16, 1082-1106.

Hahn, S., Loonen, M.J.J.E., Klaassen, M., 2011. The reliance on distant resources for egg formation in high Arctic breeding barnacle geese Branta leucopsis. J. Avian Biol. 42, 159-168.

Hamel, S., Garel, M., Festa-Bianchet, M., Gaillard, J.M., Cote, S.D., 2009. Spring normalized difference vegetation index (NDVI) predicts annual variation in timing of peak faecal crude protein in mountain ungulates. J. Appl. Ecol. 46, 582-589.

Hübner, C.E., 2006. The importance of pre-breeding areas for the Arctic Barnacle Goose Branta leucopsis. Ardea 94, 701-713.

Huete, A., Didan, K., Miura, T., Rodriguez, E.P., Gao, X., Ferreira, L.G., 2002. Overview of the radiometric and biophysical performance of the MODIS vegetation indices. Remote Sens. Environ. 83, 195-213.

IPCC, 2007. Climate Change 2007: Synthesis Report. Contribution of Working Groups I, II and III to 534 the Fourth Assessment Report of the Intergovernmental Panel on Climate Change, Geneva, Switzerland.

Jia, G.S.J., Epstein, H.E., Walker, D.A., 2003. Greening of arctic Alaska 1981-2001. Geophys. Res. Lett. 30, 1-4.

Jonsson, A.M., Eklundh, L., Hellstrom, M., Barring, L., Jonsson, P., 2010. Annual changes in MODIS vegetation indices of Swedish coniferous forests in relation to snow dynamics and tree phenology. Remote Sens. Environ. 114, 2719-2730. 
Kerby, J., Post, E., 2013. Reproductive Phenology of Large Mammals, Phenology: An Integrative Environmental Science. Springer, pp. 467-479.

Kerr, J.T., Ostrovsky, M., 2003. From space to species: ecological applications for remote sensing. Trends Ecol. Evol. 18, 299-305.

Kölzsch, A., Bauer, S., Boer, R.d., Griffin, L., Cabot, D., Exo, K.M., Van der Jeugd, H., Nolet, B.A., 2014. Forecasting spring from afar? Timing of migration and predictability of phenology along different migration routes of an avian herbivore. J. Anim. Ecol. 84, 272-283.

Lantinga, E.A., 1985. Productivity of Grasslands Under Continuous and Rotational Grazing. University of Wageningen, The Netherlands.

Lessells, C., Boag, P.T., 1987. Unrepeatable repeatabilities: a common mistake. Auk 104, 116-121.

Loe, L., Bonenfant, C., Mysterud, A., Gaillard, J.M., Langvatn, R., Klein, F., Calenge, C., Ergon, T., Pettorelli, N., Stenseth, N., 2005. Climate predictability and breeding phenology in red deer: timing and synchrony of rutting and calving in Norway and France. J. Anim. Ecol. 74, 579-588.

Lourenço, P.M., Kentie, R., Schroeder, J., Groen, N.M., Hooijmeijer, J.C., Piersma, T., 2011. Repeatable timing of northward departure, arrival and breeding in Black-tailed Godwits Limosa l. limosa but no domino effects. J. Ornithol. 152, 1023-1032.

Madsen, J., Cracknell, G., Fox, T., 1999. Goose Populations of the Western Palearctic: A Review of Status and Distribution. National Environmental Research Institute Rønde.

Marshal, J.P., Bleich, V.C., Krausman, P.R., Reed, M.L., Andrew, N.G., 2006. Factors affecting habitat use and distribution of desert mule deer in an arid environment. Wildl. Soc. Bull. 34, 609-619.

Maselli, F., Petkov, L., Maracchi, G., 1998. Extension of climate parameters over the land surface by the use of NOAA-AVHRR and ancillary data. Photogramm. Eng. Remote Sens. 64, 199-206.

Mathworks, 2013. Matlab, The Language of Technical Computing. Mathworks, Inc., USA

McMaster, G.S., Wilhelm, W.W., 1997. Growing degree-days: one equation, two interpretations. Agric. For. Meteorol. 87, 291-300.

Menzel, A., Sparks, T.H., Estrella, N., Koch, E., Aasa, A., Ahas, R., Alm-Kubler, K., Bissolli, P., Braslavska, O., Briede, A., Chmielewski, F.M., Crepinsek, Z., Curnel, Y., Dahl, A., Defila, C., Donnelly, A., Filella, Y., Jatcza, K., Mage, F., Mestre, A., Nordli, O., Penuelas, J., Pirinen, P., Remisova, V., Scheifinger, H., Striz, M., Susnik, A., Van Vliet, A.J.H., Wielgolaski, F.E., Zach, S., Zust, A., 2006. European phenological response to climate change matches the warming pattern. Glob. Change Biol. $12,1969-1976$

Mueller, T., Olson, K.A., Fuller, T.K., Schaller, G.B., Murray, M.G., Leimgruber, P., 2008. In search of forage: predicting dynamic habitats of Mongolian gazelles using satellite-based estimates of vegetation productivity. J. Appl. Ecol. 45, 649-658.

Muñoz, A.-R., Márquez, A.L., Real, R., 2015. An approach to consider behavioral plasticity as a source of uncertainty when forecasting species' response to climate change. Ecol. Evol., 1-15.

Myneni, R.B., Hall, F.G., Sellers, P.J., Marshak, A.L., 1995. The interpretation of spectral vegetation indexes. IEEE Trans. Geosci. Remote Sens. 33, 481-486.

Myneni, R.B., Keeling, C., Tucker, C., Asrar, G., Nemani, R., 1997. Increased plant growth in the northern high latitudes from 1981 to 1991. Nature 386, 698-702.

Nakagawa, S., Schielzeth, H., 2010. Repeatability for Gaussian and non-Gaussian data: a practical guide for biologists. Biol. Rev. 85, 935-956.

Nemani, R.R., Keeling, C.D., Hashimoto, H., Jolly, W.M., Piper, S.C., Tucker, C.J., Myneni, R.B., Running, S.W., 2003. Climate-driven increases in global terrestrial net primary production from 1982 to 1999. Science 300, 1560-1563.

Owen, M., 1980. Wild Geese of the World. B. T. Batsford Ltd., London, UK.

Pearce-Higgins, J., Yalden, D., Whittingham, M., 2005. Warmer springs advance the breeding phenology of golden plovers Pluvialis apricaria and their prey (Tipulidae). Oecologia $143,470-476$

Pettorelli, N., Vik, J.O., Mysterud, A., Gaillard, J.-M., Tucker, C.J., Stenseth, N.C., 2005. Using the satellite-derived NDVI to assess ecological responses to environmental change. Trends Ecol. Evol. 20, 503-510.

Pinheiro, J.C., Bates, D.M., 2009. Mixed-Effects Models in S and S-Plus. SpringerVerlag, New York.
Prop, J., Black, J.M., Shimmings, P., 2003. Travel schedules to the high arctic: barnacle geese trade-off the timing of migration with accumulation of fat deposits. Oikos $103,403-414$

Prop, J., de Vries, J., 1993. Impact of snow and food conditions on the reproductive performance of barnacle geese Branta leucopsis. Ornis Scand. 24, 110-121.

Pulido, F., Berthold, P., 2003. Quantitative genetic analysis of migratory behaviour. In: Berthold, P., Gwinner, E., Sonnenschein, E. (Eds.), Avian Migration. Springer, Berlin, Heidelberg.

R Core Team, 2014. R: A Language and Environment for Statistical Computing. R Foundation for Statistical Computing, Vienna, Austria.

Reed, B.C., Brown, J.F., Vanderzee, D., Loveland, T.R., Merchant, J.W., Ohlen, D.O., 1994. Measuring pheological variability from satellite imagery. J. Veg. Sci. 5, 703-714.

Root, T.L., Price, J.T., Hall, K.R., Schneider, S.H., Rosenzweig, C., Pounds, J.A., 2003. Fingerprints of global warming on wild animals and plants. Nature 421, 57-60.

Schwartz, M.D., 2003. Phenoclimatic Measures, Phenology: An Integrative Environmental Science. Springer, pp. 331-343.

Sedinger, J.S., Flint, P.L., 1991. Growth rate is negatively correlated with hatch date in Black Brant. Ecology, 496-502.

Shariatinajafabadi, M., Wang, T., Skidmore, A.K., Toxopeus, A.G., Kölzsch, A., Nolet, B.A., Exo, K.M., Griffin, L., Stahl, J., Cabot, D., 2014. Migratory herbivorous waterfowl track satellite-derived green wave index. PLOS ONE 9, e108331.

Skidmore, A.K., Ferwerda, J.G. 2008. Resource distribution and dynamics. In: Prins, H.H.T. Langevelde, F.V.(Eds.), Resource Ecology Spatial and Temporal Dynamics of Foraging. Springer, Dordrecht, pp. 57-77.

Slayback, D.A., Pinzon, J.E., Los, S.O., Tucker, C.J., 2003. Northern hemisphere photosynthetic trends 1982-99. Glob. Change Biol. 9, 1-15.

Stone, R.S., Dutton, E.G., Harris, J.M. Longenecker, D. 2002. Earlier spring snowmelt in northern Alaska as an indicator of climate change. J. Geophys. Res.: Atmos. (1984-2012) 107, ACL 10-11-ACL 10-13.

Teplitsky, C., Mills, J.A., Alho, J.S., Yarrall, J.W., Merilä, J., 2008. Bergmann's rule and climate change revisited: disentangling environmental and genetic responses in a wild bird population. Proc. Natl. Acad. Sci. 105, 13492-13496.

Tombre, I.M., Høgda, K.A., Madsen, J., Griffin, L.R., Kuijken, E., Shimmings, P., Rees, E., Verscheure, C., 2008. The onset of spring and timing of migration in two Arctic nesting goose populations: the pink-footed goose Anser bachyrhynchus and the barnacle goose Branta leucopsis. J. Avian Biol. 39, 691-703.

Tullus, A. Kupper, P., Sellin, A. Parts, L., Sober, J., Tullus, T., Lohmus, K., Sober, A., Tullus, H., 2012. Climate change at northern latitudes: rising atmospheric humidity decreases transpiration, N-uptake and growth rate of hybrid aspen. PLOS ONE 7, e42648.

Tveraa, T., Stien, A., Bårdsen, B.-J.,Fauchald, P. 2013. Population densities, vegetation green-up, and plant productivity: impacts on reproductive success and juvenile body mass in reindeer. PLOS ONE 8, e56450.

Van der Graaf, A.G., 2006. Geese on a Green Wave: Flexible Migrants in a Changing World. University of Groningen, Groningen.

Van der Graaf, S., Stahl, J., Klimkowska, A., Bakker, J.P., Drent, R.H., 2006. Surfing on a green wave - how plant growth drives spring migration in the Barnacle Goose Branta leucopsis. Ardea 94, 565-577.

Van Eerden, M.R., Drent, R.H., Stahl, J., Bakker, J.P., 2005. Connecting seas: western Palaearctic continental flyway for water birds in the perspective of changing land use and climate Glob. Change Biol, 11, 894-908.

Van Wijk, R.E., Kölzsch, A., Kruckenberg, H., Ebbinge, B.S., Muskens, G., Nolet, B.A., 2012. Individually tracked geese follow peaks of temperature acceleration during spring migration. Oikos 121, 655-664.

Visser, M.E., Both, C., 2005. Shifts in phenology due to global climate change: the need for a yardstick. Proc. R. Soc. B: Biol. Sci. 272, 2561-2569.

Wang, J.Y., 1960. A critique of the heat unit approach to plant-response studies. Ecology 41, 785-790.

White, M.A., Thornton, P.E., Running, S.W., 1997. A continental phenology model for monitoring vegetation responses to interannual climatic variability. Glob. Biogeochem. Cycles 11, 217-234.

Žalakevicius, M., 1997. Bird migration and climate change. Acta Zool. Lit. 6, 20-30. 